HEPATITIS

\title{
Insulin resistance is a cause of steatosis and fibrosis progression in chronic hepatitis $C$
}

\author{
L Fartoux, A Poujol-Robert, J Guéchot, D Wendum, R Poupon, L Serfaty
}

Gut 2005;54:1003-1008. doi: 10.1136/gut.2004.050302

See end of article for authors' affiliations

Correspondence to: Dr L Serfaty, Service d'Hépatologie, Hopital Saint-Antoine, 184 rue du Faubourg Saint-Antoine, 75571 Paris cedex 12, France; lawrence.serfaty@ sat.ap-hop-paris.fr

Revised version received 1 October 2004

Accepted for publication 26 October 2004
Background: Insulin resistance is a frequent feature of chronic hepatitis $C$. Whether insulin resistance could be the cause or consequence of steatosis and fibrosis is unknown. The ability of HCV genotype 3 to promote steatosis by itself provides an unique opportunity to answer this question.

Aims: The aim of the present study was to assess the relationships between insulin resistance, steatosis, and fibrosis according to genotype in 141 non-diabetic patients with biopsy proven non-cirrhotic chronic hepatitis C.

Methods: All patients had fasting serum glycaemia and insulinaemia measurements. Insulin resistance was evaluated using the homeostasis model assessment (HOMA IR) method. Liver steatosis was determined according to hepatitis $C$ virus genotype ( 1 or 3). Logistic regression and multivariate regression analysis were used to identify variables independently associated with insulin resistance, fatty liver, and fibrosis. Results: Although steatosis and fibrosis were more severe in genotype 3 patients, median HOMA IR was significantly higher in patients with genotype 1 related steatosis than in those with genotype 3 related steatosis $(2.1 \vee 1 ; p=0.001)$. Independent risk factors for steatosis were insulin resistance in genotype 1 patients $(p=0.001)$ and viral load in genotype 3 patients $(p=0.003)$. Among genotype 1 patients, independent parameters associated with insulin resistance were age $(p=0.04)$ and steatosis $(p=0.004)$. Steatosis was associated with more severe fibrosis whatever the genotype $(p=0.002)$. Among genotype 1 patients, although there was a significant relationship between circulating insulin level and fibrosis stage $(p=0.006)$, only steatosis and inflammatory score were independently associated with fibrosis.

Conclusion: This study shows that insulin resistance is the cause rather than the consequence of steatosis and fibrosis in genotype 1 patients and that increased circulating insulin is a risk factor for fibrosis through insulin resistance induced steatosis.
L iver steatosis is common in chronic hepatitis $\mathrm{C}$ virus infection (HCV). ${ }^{1-3}$ Evidence supporting a detrimental role - for steatosis in liver fibrosis progression in chronic hepatitis C has been provided recently. Several studies have shown that either fat accumulation in the liver or worsening are strong and independent predictors of the severity and progression of fibrosis in chronic hepatitis C infection, irrespective of the viral genotype involved. ${ }^{4-10}$ Two main mechanisms have been proposed to account for the high prevalence of steatosis in chronic hepatitis C. Firstly, in patients infected with genotype 3, the degree of steatosis is correlated with the level of viral load, ${ }^{411}$ suggesting that HCV could alter fatty acid metabolism and/or export in hepatocytes. ${ }^{12}{ }^{13}$ Secondly, type 2 diabetes and more generally insulin resistance is highly frequent in chronic HCV infection, as established by several recent epidemiological studies. ${ }^{14-21}$ Whether or not insulin resistance is a player in the development of the histological lesions of chronic hepatitis C-as in alcoholic or non-alcoholic steatohepatitis-or simply the consequence of viral infection and liver injury is debated. Recently, Shintani et al have shown that insulin resistance preceded the occurrence of steatosis in transgenic mice expressing HCV core protein, suggesting that insulin resistance is not a consequence of hepatic steatosis in these mice..$^{22}$ This issue is of obvious practical importance because appropriate treatment should be based on the pathophysiological process involved in the disease. In the present study we addressed the following questions: is insulin resistance the cause or the consequence of steatosis and fibrosis in chronic hepatitis C? In other words, is insulin resistance, at least in part, responsible for the occurrence and worsening of steatosis and fibrosis? What are the determinants of insulin resistance in chronic hepatitis $\mathrm{C}$ ? The unique ability of $\mathrm{HCV}$ genotype 3 to promote by itself steatosis provides the opportunity to clarify and unravel the complex relationships between insulin resistance, steatosis, and fibrosis.

\section{PATIENTS AND METHODS}

\section{Study population}

Between June 2001 and May 2002, 192 consecutive patients with chronic hepatitis $C$ underwent liver biopsy in our liver unit. All subjects had positive HCV viraemia, as detected by reverse transcription-polymerase chain reaction (RT-PCR) (Amplicor; Roche Diagnostic Systems, Branchburg, New Jersey, USA) and increased alanine aminotransferase (ALT) activity. Patients were retrospectively screened according to the following criteria: (1) the presence of non-cirrhotic chronic hepatitis on liver biopsy specimens greater than $10 \mathrm{~mm}$; (2) no previous antiviral treatment; (3) no personal history of diabetes or a fasting serum glucose $<7 \mathrm{mmol} / \mathrm{l}$; (4) alcohol intake $<20$ g/day; (5) no regular use of drugs known to induce steatosis (for example, corticosteroids, valproic acid, amiodarone, perhexiline maleate, tamoxifen); (6) absence of serum hepatitis B surface antigen; (7) absence of co-existing chronic liver disease, such as autoimmune hepatitis, primary biliary cirrhosis, sclerosing cholangitis, haemochromatosis, Wilson's disease, or $\alpha_{1}$ antitrypsin deficiency; and (8) absence of human immunodeficiency virus antibodies. A total of 141 patients met these criteria.

Abbreviations: $H C V$, hepatitis $C$ virus; RT-PCR, reverse transcriptionpolymerase chain reaction; BMI, body mass index; ALT, alanine aminotransferase; HOMA, homeostasis model assessment; IRS-1, insulin receptor substrate 1 
Excluded patients had one or more exclusion criteria: cirrhosis in 17, alcohol intake $>20 \mathrm{~g}$ /day in 34, personal history of diabetes in six, fasting serum glucose $>7 \mathrm{mmol} / \mathrm{l}$ in 16, previous antiviral treatment in five, and inadequate biopsy in 31 .

\section{Clinical parameters}

The following data were recorded at the time of liver biopsy: age, sex, duration of HCV infection, estimated as the time elapsed since the date of contamination in patients with known risk factors (for example, date of transfusion or beginning of intravenous drug use) and liver biopsy, body mass index (BMI), and mean daily alcohol intake between the date of contamination and diagnosis of HCV infection. BMI was calculated as body weight $(\mathrm{kg})$ divided by squared height in metres $\left(\mathrm{kg} / \mathrm{m}^{2}\right)$. Patients were interviewed using a standard questionnaire for their alcohol intake in the past five years. ${ }^{23}$

\section{Methods}

\section{Laboratory determinations}

After an overnight fast of 10 hours, venous blood samples were drawn to determine serum levels of the following parameters: alanine aminotransferase (ALT), aspartate aminotransferase, plasma glucose concentration, insulin, and C peptide. All studies were performed before 9am. Plasma glucose concentration was measured by a glucose oxidase method on a vitros 750 analyser (Johnson and Johnson Clinical Diagnostics, Rochester, New York, USA). Serum insulin was measured by monoclonal immunoradiometric assay (CIS Bio International, Gif sur Yvette, France). Serum C peptide was estimated by a immunoradiometric assay (CIS Bio International). The index of insulin resistance was calculated on the basis of fasting values for glycaemia and insulinaemia, according to the homeostasis model assessment (HOMA) method. ${ }^{24}$ The formula for the HOMA model is as follows:

insulin resistance $($ HOMA IR $)=$ fasting insulinaemia $(\mu \mathrm{U} /$ $\mathrm{ml}) \times$ fasting glycaemia $(\mathrm{mmol} / \mathrm{l}) / 22.5$.

Insulin resistance, determined by this method, correlates closely with more complex techniques, such as the euglycaemic clamp method, in both diabetic and non-diabetic subjects. ${ }^{25}{ }^{26}$ Because serum insulin levels may be increased secondary to advanced liver fibrosis, insulin secretion was compared in patients with and without fibrosis using the serum C peptide/insulin ratio. C peptide and insulin are secreted in equimolar amounts, and serum $\mathrm{C}$ peptide is not significantly cleared by the liver. ${ }^{27}$

\section{Virological methods}

All subjects were reactive for anti-HCV antibodies using a third generation enzyme immunoassay EIA (Ortho HCV 3.0 Elisa (Ortho Diagnostic Systems, Raritan, New Jersey, USA) or Monolisa anti-HCV (Sanofi Diagnostics Pasteur, Marnesla-Coquette, France)). All patients were tested for HCV RNA by RT-PCR (Amplicor HCV; Roche Diagnostic Systems). HCV RNA was quantified by Quantiplex HCV RNA 2.0 Assay (Chiron Diagnostics, Emeryville, California, USA). HCV genotypes were determined using the Inno-Lipa II HCV (Innogenetics, Ghent, Belgium).

\section{Histological evaluation}

Paraffin embedded biopsies were analysed by a single pathologist unaware of the clinical and biological data, except for the presence of chronic hepatitis C. This analysis was performed following haematoxylin-phloxin-safran, Perls, and picrosirius red staining, using the METAVIR group items. Steatosis was graded according to the percentage of hepatocytes containing cytoplasmic vacuoles. Only macrovesicular steatosis was taken into account. Steatosis was classified as significant when more than $10 \%$ of hepatocytes were affected. Hepatitis was finally graded and staged using the METAVIR scoring system. ${ }^{28}{ }^{29}$ Hepatic iron concentration was determined according to the Barry and Sherlock method. ${ }^{30}$

Each liver biopsy specimen was analysed twice by the same pathologist in a blinded manner, with good intraobserver concordance.

\section{Statistical analysis}

Qualitative values are expressed as percentages and were compared using Fisher's exact test. Quantitative values are expressed as medians (range) and were compared using the Mann-Whitney or Kruskal-Wallis test, when more than two classes, or Spearman's correlation test. For statistical analysis, patients infected with genotypes other than 3 were

Table 1 Characteristics of patients according to hepatitis $C$ virus genotype

\begin{tabular}{|c|c|c|c|}
\hline & $\begin{array}{l}\text { Genotype } 1 \\
(n=113)\end{array}$ & $\begin{array}{l}\text { Genotype } 3 \\
(n=28)\end{array}$ & p Value* \\
\hline Age (y) & $43(20-72)$ & $42.5(30-63)$ & NS \\
\hline Sex ratio $(M / F)$ & 1.3 & 1.4 & NS \\
\hline Disease duration $(y) \dagger$ & $18(5-41)$ & $17(4-25)$ & NS \\
\hline Alcohol (g/day) & $0(0-20)$ & $0(0-20)$ & NS \\
\hline BMI $\left(\mathrm{kg} / \mathrm{m}^{2}\right)$ & $23.6(14-39)$ & $23(19-32)$ & NS \\
\hline ALT (UI/I) & $47(11-264)$ & 50 (19-159) & NS \\
\hline Viral load $\left(10^{6} \mathrm{Eq} / \mathrm{ml}\right)$ & $5.9(0.2-120)$ & $9.1(0.2-104)$ & NS \\
\hline Glycaemia (mm/l) & $4.7(2.8-6.9)$ & $4.7(3.6-6.7)$ & NS \\
\hline Insulinaemia ( $\mu \mathrm{U} / \mathrm{ml})$ & $5.8(0.7-51)$ & $5.3(2-30)$ & NS \\
\hline C peptide (nm/l) & $0.6(0.1-3.2)$ & $0.7(0.3-1.4)$ & NS \\
\hline HOMA IR & $1.2(0.1-8.2)$ & $1(0.3-6.6)$ & NS \\
\hline Activity score >1 (\%) & 31 & 29 & NS \\
\hline Fibrosis score $>1(\%)$ & 30 & 54 & 0.03 \\
\hline$\%$ of steatosis & $0(0-60)$ & $10(0-80)$ & 0.0007 \\
\hline \multicolumn{4}{|l|}{ Steatosis } \\
\hline$<10(\%)$ & 71 & 40 & $<0.0001$ \\
\hline $10-30(\%)$ & 25 & 24 & \\
\hline$>30(\%)$ & 4 & 36 & \\
\hline
\end{tabular}

Values are median (range) or percentage.

$\mathrm{BMI}$, body mass index; ALT, alanine aminotransferase; HOMA IR, homeostasis model assessment for insulin resistance.

†ln 80 patients with known risk factors

*Fisher's exact test or Mann-Whitney test. 
Table 2 Characteristics of patients according to hepatitis $C$ virus genotypes and steatosis

\begin{tabular}{|c|c|c|c|c|c|}
\hline & \multicolumn{2}{|l|}{ Genotype 1} & \multicolumn{2}{|l|}{ Genotype 3} & \multirow[b]{2}{*}{ p Value* } \\
\hline & $\begin{array}{l}\text { Steatosis }<10 \% \\
(n=80)\end{array}$ & $\begin{array}{l}\text { Steatosis } \geqslant 10 \% \\
(n=33)\end{array}$ & $\begin{array}{l}\text { Steatosis }<10 \% \\
(n=13)\end{array}$ & $\begin{array}{l}\text { Steatosis } \geqslant 10 \% \\
(n=15)\end{array}$ & \\
\hline Age (y) & 41 & $49 \ddagger$ & 44.5 & 43 & 0.0008 \\
\hline Sex ratio (M/F) & 1.22 & 1.54 & 1 & 2.75 & NS \\
\hline Disease duration (y)† & 18 & 18.5 & 16 & 17 & NS \\
\hline Alcohol (g/day) & 0 & 0 & 0 & 0 & NS \\
\hline BMI & 22.8 & $25.3 \ddagger$ & 22.8 & 23 & 0.0003 \\
\hline ALT (IU/I) & 46 & 60 & 47 & 72 & NS \\
\hline Insulinaemia $(\mu \mathrm{U} / \mathrm{ml})$ & 4.8 & $9.4 \ddagger$ & 5.4 & 5.2 & $<0.0001$ \\
\hline C peptide (nmol/l) & 0.6 & $0.9 \ddagger$ & 0.5 & 0.6 & 0.01 \\
\hline HOMA IR & 1.1 & $2.1 \ddagger$ & 1.1 & 1 & 0.001 \\
\hline Viral load $\left(10^{6} \mathrm{Eq} / \mathrm{ml}\right)$ & 6.4 & 3.4 & 2.6 & $33.5 \ddagger$ & 0.009 \\
\hline Activity score & 1 & 1 & 1 & 1 & NS \\
\hline Fibrosis score & 1 & $2 \ddagger$ & 1 & $2 \ddagger$ & 0.002 \\
\hline Percentage of steatosis & 0 & 20 & 1.5 & $40 \ddagger$ & $<0.0001$ \\
\hline Hepatic iron $(\mu \mathrm{mol} / \mathrm{g})$ & 9.4 & 12.2 & 9.2 & 6.7 & NS \\
\hline \multicolumn{6}{|c|}{$\begin{array}{l}\text { Values are medians. } \\
\text { BMI, body mass index; ALT, alanine aminotransferase; HOMA IR, homeostasis model assessment for insulin } \\
\text { resistance. } \\
\text { †ln } 80 \text { patients with known risk factors. } \\
\text { *Fisher's exact test or Kruskal-Wallis test; } \ddagger \text { Mann-Whitney test, } \mathrm{p}<0.05 \text {. }\end{array}$} \\
\hline
\end{tabular}

collected into a single group termed "genotype 1 patients". Risk factors for insulin resistance were assessed in genotype 1 patients by correlating HOMA IR with the following parameters: age at liver biopsy, sex ratio, disease duration, BMI, mean daily alcohol intake, ALT activity, viral load, activity score, fibrosis score, percentage of steatosis, and intrahepatic iron concentration. Risk factors for steatosis were assessed separately in genotype 1 and genotype 3 patients by correlating the percentage of steatosis to the following parameters: age at liver biopsy, sex ratio, disease duration, BMI, mean daily alcohol intake, viral load, HOMA IR, activity score, and intrahepatic iron concentration. Independent parameters were assessed by multiple regression. The role of insulin in fibrosis progression was assessed in genotype 1 patients. The following parameters were included in a logistic regression model, with extensive fibrosis (score $>1$ ) as a dependent variable: age at liver biopsy, sex ratio, BMI, fasting serum insulin, activity score, and percentage of steatosis. Differences were considered significant at a $\mathrm{p}$ value of $<0.05$.

\section{RESULTS}

\section{Characteristics of genotype 1 and genotype 3 infected patients}

A total of 141 patients met the inclusion criteria. The distribution of HCV genotypes was as follows: 78 patients were infected by genotype 1, eight by genotype 2, 28 by

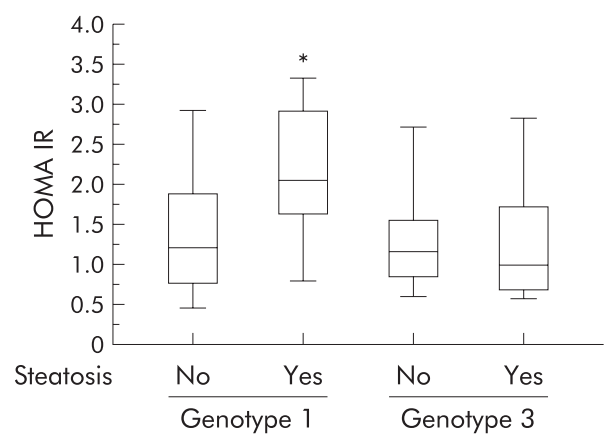

Figure 1 Distribution of homeostasis model assessment for insulin resistance (HOMA IR) according to steatosis and hepatitis $C$ virus genotype. ${ }^{*} \mathrm{p}<0.05$. genotype 3, 16 by genotype 4, four by genotype 5 , one by genotype 6, and six had an undetermined genotype. The 113 patients infected with genotypes other than 3 were collected into a single group termed "genotype 1 patients" and compared with the 28 patients infected with genotype 3 . Their characteristics are listed in table 1. Both steatosis and fibrosis were more frequent and more severe in patients infected with genotype 3 than in those infected with genotype 1. Other characteristics, in particular those with a potential impact on both steatosis and fibrosis (namely, age, disease duration, alcohol consumption, BMI, serum ALT activity, HOMA index and histological activity score), did not differ between the two groups.

\section{Insulin resistance is associated with genotype 1 related steatosis but not with genotype 3 related steatosis}

Table 2 shows the main features of patients infected with genotypes 1 and 3 according to the presence or absence of significant steatosis. Genotype 1 patients with a fatty liver were older, had a higher BMI, and were more frequently insulin resistant than those without a fatty liver or those infected with genotype 3, even with marked steatosis. These latter patients had a higher median viral load than that found in the other groups (table 2). HOMA IR distribution in patients is presented in fig 1. Median HOMA IR was significantly higher in patients with genotype 1 related steatosis than in those with genotype 3 related steatosis or patients without steatosis. In genotype 1 patients, univariate analysis showed four parameters significantly linked with the degree of steatosis: age, BMI, HOMA IR, and hepatic iron

Table 3 Risk factors for steatosis in univariate and multivariate analysis in patients infected with genotype 1

\begin{tabular}{|c|c|c|c|c|c|}
\hline & \multicolumn{2}{|c|}{ Univariate analysis } & \multicolumn{3}{|c|}{ Multivariate analysis } \\
\hline & Coefficient & p Value* & Coefficient & SE & p Value ** \\
\hline Age & 0.39 & $<0.0001$ & 0.096 & 0.085 & 0.32 \\
\hline BMI & 0.42 & $<0.0001$ & 0.18 & 0.22 & 0.06 \\
\hline HOMA IR & 0.56 & $<0.0001$ & 0.315 & 0.7 & 0.001 \\
\hline Hepatic iron & 0.22 & 0.03 & 0.027 & 0.028 & 0.75 \\
\hline
\end{tabular}

BMI, body mass index; HOMA, homeostasis model assessment. *Spearman's test.

${ }^{* *}$ Multiple regression. 


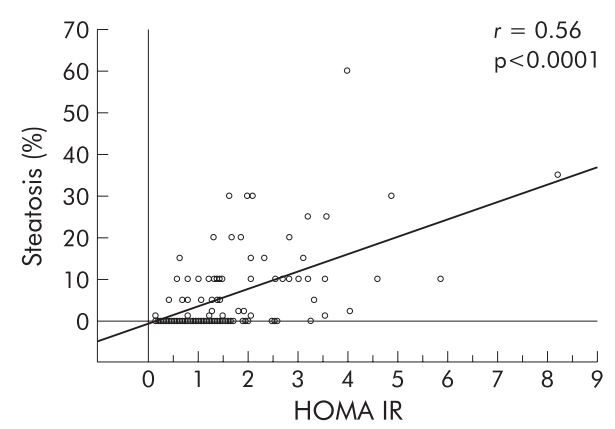

Figure 2 Percentage of steatosis according to homeostasis model assessment for insulin resistance (HOMA IR) in genotype 1 patients.

concentration (table 3). Multivariate analysis showed that HOMA IR was the only variable independently related to fatty liver in genotype 1 infected patients (table 3, fig 2) while in patients infected with genotype 3, viral load was the only variable associated with fatty liver $(r=0.64, \mathrm{p}=0.003$, fig 3$)$.

\section{Insulin resistance is specifically associated with steatosis but not with fibrosis in genotype 1 infected patients}

Genotype 1 infected patients with extensive fibrosis (histological score $>1$ ) had a higher median HOMA IR than others (1.8 $v 1.0 ; p=0.0001)$. However, the association was no longer significant after adjustment for the degree of steatosis (fig 4). Serum C peptide/insulin ratio was similar in patients with or without extensive fibrosis $(0.1(0.03-0.6) v 0.1(0.03-$ $0.4) ; \mathrm{p}=0.8$ ).

\section{Risk factors for insulin resistance in patients infected with genotype 1}

In univariate analysis, seven parameters were significantly correlated with HOMA IR in patients infected with genotype 1: age at liver biopsy, disease duration, BMI, ALT activity, activity score, fibrosis score, and percentage of steatosis (table 4$)$. In multivariate analysis $\left(r^{2}=0.28\right)$, only age and degree of steatosis were independently linked to HOMA IR (table 4).

\section{Risk factors for extensive fibrosis in patients infected with genotype 1}

Among genotype 1 patients, 34 (30\%) had extensive fibrosis $($ score $>1)$. In univariate analysis, six parameters were significantly associated with fibrosis: age, male sex, BMI, insulinaemia, activity score, and steatosis (table 5). Alcohol consumption and duration since contamination were not significantly different between patients with or without extensive fibrosis $(4.7(10) \vee 6.6(11.8) \mathrm{g} /$ day $(\mathrm{p}=0.4)$ and $18.5(9.7) \vee 19.4(7.6)$ years $(\mathrm{p}=0.35)$, respectively). When we compared non-drinker patients $(n=89)$ with those drinking small amounts of alcohol $(n=29)$, the prevalence of extensive fibrosis was not significantly different between the groups ( $32 \vee 24 \%$, respectively; $\mathrm{p}=0.04)$. In multivariate analysis $\left(r^{2}=0.21\right)$, only steatosis and activity score were independently associated with extensive fibrosis (table 5).

\section{DISCUSSION}

This study confirms that the pathophysiology of fatty liver associated chronic hepatitis $\mathrm{C}$ is different in patients infected with genotype 1 and 3 . The study also shows that insulin resistance in patients infected with genotype 1 is the cause rather than the consequence of hepatic steatosis and fibrosis, and suggests that increased circulating insulin is a risk factor for fibrosis through insulin resistance induced steatosis.

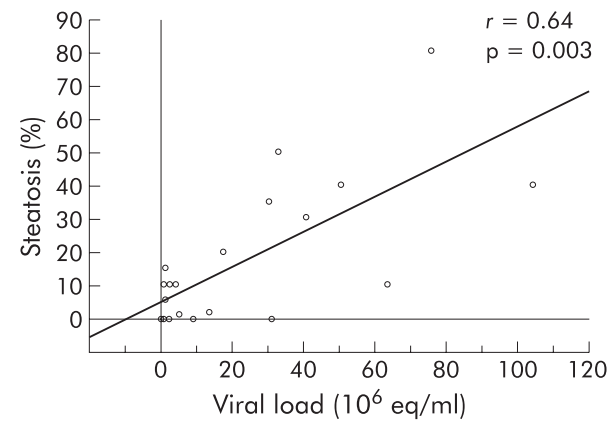

Figure 3 Percentage of steatosis according to hepatitis $C$ virus viral load in genotype 3 patients.

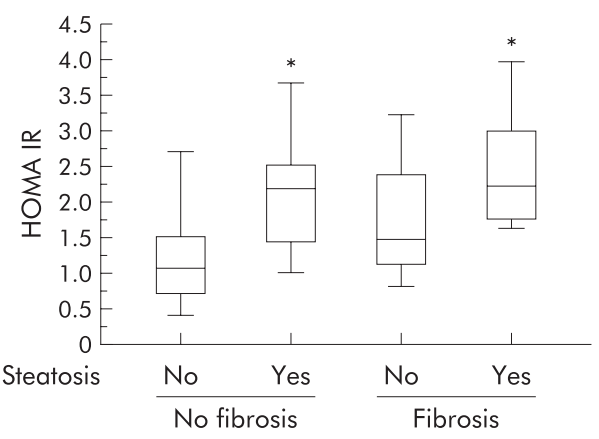

Figure 4 Distribution of homeostasis model assessment for insulin resistance (HOMA IR) according to steatosis and fibrosis in genotype 1 infected patients. ${ }^{*} \mathrm{p}<0.05$.

Although steatosis was more severe in patients infected with genotype 3, insulin resistance was associated with steatosis only in patients infected with genotype 1. Insulin resistance depends mainly on age and is a major risk factor for steatosis, independent of BMI. Steatosis was associated with more severe fibrosis, whatever the genotype, supporting the major role of steatosis, whatever its cause, in the progression of fibrosis. Indeed, while univariate analysis identified a significant link between circulating insulin level and fibrosis stage, multivariate analysis revealed that steatosis, but not insulin, was independently associated with fibrosis, suggesting an indirect effect of the circulating

Table 4 Parameters significantly associated with homeostasis model assessment for insulin resistance (HOMA IR) in univariate and multivariate analysis in patients infected with genotype 1

\begin{tabular}{|c|c|c|c|c|c|}
\hline & \multicolumn{2}{|c|}{ Univariate analysis } & \multicolumn{3}{|c|}{ Multivariate analysis } \\
\hline & Coefficient & p Value* & Coefficient & SE & p Value ** \\
\hline Age & 0.38 & $<0.0001$ & 0.203 & 0.012 & 0.04 \\
\hline $\begin{array}{c}\text { Duration of } \\
\text { disease }\end{array}$ & 0.25 & 0.04 & 0.085 & 0.018 & 0.33 \\
\hline $\mathrm{BMI}$ & 0.41 & $<0.0001$ & 0.103 & 0.03 & 0.27 \\
\hline ALT & 0.25 & 0.008 & 0.122 & 0.003 & 0.24 \\
\hline Activity score & 0.39 & 0.002 & 0.024 & 0.225 & 0.8 \\
\hline Fibrosis score & 0.46 & 0.0001 & 0.069 & 0.181 & 0.47 \\
\hline$\%$ of steatosis & 0.56 & $<0.0001$ & 0.27 & 0.013 & 0.004 \\
\hline \multicolumn{6}{|c|}{$\begin{array}{l}\text { BMI, body mass index; ALT, alanine aminotransferase; HOMA, } \\
\text { homeostasis model assessment. } \\
\text { *Spearman's test; }{ }^{* *} \text { multiple regression. } \\
\text { †ln } 62 \text { patients with known risk factors. Taking disease duration into } \\
\text { account did not change the results. }\end{array}$} \\
\hline
\end{tabular}


Table 5 Risk factors for extensive fibrosis in univariate and multivariate analysis in patients infected with genotype 1

\begin{tabular}{|c|c|c|c|c|c|}
\hline & \multicolumn{3}{|c|}{ Univariate analysis } & \multicolumn{2}{|c|}{ Multivariate analysis } \\
\hline & $\begin{array}{l}\text { Fibrosis } \leqslant 1 \\
(n=79)\end{array}$ & $\begin{array}{l}\text { Fibrosis }>1 \\
(n=34)\end{array}$ & p Value* & p Value ${ }^{* *}$ & OR (Cl) \\
\hline Age $>55$ yrs (\%) & 11 & 35 & 0.007 & 0.14 & - \\
\hline Male sex $(\%)$ & 50 & 70 & 0.06 & 0.08 & - \\
\hline $\mathrm{BMI}>25(\%)$ & 27 & 53 & 0.02 & 0.3 & - \\
\hline Insulin $>10 \mu \mathrm{U} / \mathrm{ml}(\%)$ & 14 & 38 & 0.006 & 0.7 & - \\
\hline Activity score >1 (\%) & 21 & 53 & 0.002 & 0.016 & $3.4(1.3-9.4)$ \\
\hline Steatosis $\geqslant 10 \%(\%)$ & 19 & 53 & 0.0006 & 0.02 & $3.6(1.2-10.8)$ \\
\hline
\end{tabular}

insulin level on fibrosis stage through a steatosis related pathway.

To clarify the intricate relationship between insulin resistance, steatosis, and fibrosis, the study was performed in two groups of patients with chronic HCV infection due to genotype 1 or genotype 3 . The results of the present study confirm the cogency of this distinction as two distinct mechanisms appear to operate in HCV associated fatty liver. In genotype 1 infected patients, steatosis was linked to BMI, while in genotype 3 infected patients, steatosis was related to HCV viral load. Moreover, we took care to exclude patients with usual causes of steatosis, such as alcohol, drugs, or diabetes mellitus. In this selected population, the prevalence of significant steatosis $(\geqslant 10 \%)$ was still high, reaching $60 \%$ in patients infected with genotype 3 . These results are in accordance with previous studies showing a strong association between steatosis and genotype 3 infection..$^{4-11}{ }^{12}$ Because cirrhosis is a well known cause of insulin resistance, ${ }^{31}$ patients with biopsy proven cirrhosis were also excluded.

The mechanisms of development of insulin resistance in patients with chronic HCV infection are not well understood. It has been suggested that insulin resistance may result from steatosis, as excess free fatty acids could downregulate insulin receptor substrate 1 (IRS-1) signalling. ${ }^{32}$ This concept was further supported by recent evidence that reversing hepatic steatosis may improve insulin resistance in rats with diet induced fatty liver. ${ }^{33}$ Despite the significant relationship in genotype 1 infected patients, the lack of association between steatosis and insulin resistance in genotype 3 infected patients does not support this hypothesis. Shintani et al showed that insulin resistance preceded the occurrence of steatosis in transgenic mice expressing HCV core protein, suggesting that insulin resistance is not a consequence of hepatic steatosis in these mice. ${ }^{22}$ As expected, BMI was correlated with the degree of insulin resistance in univariate analysis. ${ }^{34}$ However, in multivariate analysis, the degree of insulin resistance depended mainly on the age of the patient. Finally, genotype 1 infected patients with fatty liver were more insulin resistant than genotype 3 infected patients, probably because they were older and had higher BMI values. It has been suggested that age associated decline in mitochondrial function could contribute to insulin resistance. ${ }^{35}$ Our results do not exclude other mechanisms. The higher prevalence of type 2 diabetes in patients with chronic hepatitis C suggests implementation of HCV infection itself. $^{14-20}$ Impaired IRS-1 signalling could be a possible mechanism, as recently shown in non-obese/non-diabetic patients with chronic HCV infection. ${ }^{36}$ In a large cohort study, Hui et al showed a genotype specific association between chronic HCV infection and insulin resistance. ${ }^{21}$ The significant link between genotype 1 related steatosis and insulin resistance in our study population tends to support this hypothesis.
As in previous studies, we found that steatosis ( $\geqslant 10 \%$ ) was common among patients with chronic hepatitis $\mathrm{C}$, occurring in $34 \%$ of biopsy specimens. ${ }^{1-3}$ Our data confirm the strong correlation between the degree of steatosis and level of HCV viraemia in genotype 3 infected patients. ${ }^{4}$ In patients infected with genotype 1, multivariate analysis demonstrated that insulin resistance was a risk factor for steatosis, independent of BMI. These data confirm the existence of two distinct entities: a group of patients infected with genotype 1 that may have steatosis secondary to metabolic causes such as insulin resistance, and a second group infected with genotype 3 that may have steatosis as a direct consequence of $\mathrm{HCV}$ infection.

In patients with chronic hepatitis $\mathrm{C}$, we and others have shown a significant relationship between the degree of steatosis and severity of fibrosis. ${ }^{467}$ In the present study, steatosis was associated with fibrosis, irrespective of viral genotype. Because steatosis was associated with insulin resistance in genotype 1 infected patients, fibrosis could be the result of hyperinsulinaemia. In fact, it has been demonstrated that high levels of insulin and glucose could promote fibrogenesis by stimulating the release of connective tissue growth factor, a fibrogenic growth factor, from hepatic stellate cells. ${ }^{37}$ In genotype 1 infected patients, fibrosis stage significantly correlated with circulating insulin levels in univariate analysis. When considering other potential risk factors of fibrosis, such as steatosis, insulin was no longer an independent risk factor. The relationship between steatosis and fibrosis could be explained by several other mechanisms, such as lipid peroxidation. ${ }^{38-41}$ According to the "two hits hypothesis", steatosis could increase the sensitivity of hepatocytes to oxidative stress, the second hit being HCV infection itself in patients with chronic hepatitis C. ${ }^{39}$ Production of reactive oxygen species in an in vitro model expressing HCV core protein is consistent with this hypothesis. ${ }^{42}$ The second independent risk factor for fibrosis in the present study was the histological score of activity. This result agrees well with the findings of previous longitudinal studies that showed that the necroinflammatory score was predictive of the development of severe fibrosis in patients with chronic hepatitis C..$^{43}$ In our study, neither the duration of contamination nor alcohol consumption was associated with fibrosis. The non-linear progression of fibrosis in chronic hepatitis C probably explains the former result. ${ }^{43}{ }^{44}$ In most of the studies showing a significant association between alcohol and fibrosis, the cut off value was $20 \mathrm{~g} / \mathrm{day} .^{5-7}$ In our study population, drinking less than $20 \mathrm{~g} /$ day, we did not find any significant effect of small amounts of alcohol on fibrosis.

In conclusion, increased circulating insulin is a risk factor for fibrosis in genotype 1 infected patients with chronic hepatitis $\mathrm{C}$ through insulin resistance induced steatosis. Accordingly, it may be speculated that intervention strategies to reduce insulin resistance associated with steatosis should 
target these patients. In the near future, metformin or peroxisome proliferator activated receptor $\gamma$ agonists could be interesting therapeutic options for improving steatosis and fibrosis in HCV patients with insulin resistance. ${ }^{45} 46$

\section{Authors' affiliations}

L Fartoux, R Poupon, L Serfaty, Service d'Hépatologie, Hôpital SaintAntoine, Paris, France, and Inserm U680, Universite Pierre et Marie Curie, Paris, France

A Poujol-Robert, Service d'Hépatologie, Hôpital Saint-Antoine, Paris, France

J Guéchot, Service de Biochimie, Hôpital Saint-Antoine, Paris, France

D Wendum, Service d'Anatomo-pathologie, Hôpital Saint-Antoine,

Paris, France

Conflict of interest: None declared.

\section{REFERENCES}

1 Bach N, Thung SN, Shaffner F. The histological features of chronic hepatitis C and autoimmune chronic hepatitis: a comparative analysis. Hepatology 1992; 15:572-7.

2 Schever PJ, Ashrafzadeh P, Sherlock S, et al. The pathology of hepatitis C. Hepatology 1992;15:567-71.

3 Lefkowitch JH, Schiff ER, Davis GL, et al. Pathological diagnosis of chronic hepatitis C: a multicenter comparative study with chronic hepatitis B. The Hepatitis Interventional Therapy Group. Gastroenterology 1993;104:595-603.

4 Adinolfi LE, Gambardella, Andreana A, et al. Steatosis accelerates the progression of liver damage of chronic hepatitis $C$ patients and correlates with specific HCV genotype and visceral obesity. Hepatology 2001;33:1358-64.

5 Monto A Alonzo J, Watson JJ, et al. Steatosis in chronic hepatitis C: relative contributions of obesity, diabetes mellitus, and alcohol. Hepatology 2002;36:729-36.

6 Serfaty L, Poujol-Robert A, Carbonell N, et al. Interaction between steatosis and alcohol intake on liver fibrosis progression in chronic hepatitis $C$. Am J Gastroenterol 2002:97:1807-12.

7 Hourigan LF, MacDonald GA, Purdie D, et al. Fibrosis in chronic hepatitis C correlates significantly with body mass index and steatosis. Hepatology 1999;29:1215-19.

8 Castera L, Hezode C, Roudot-Thoroval F, et al. Worsening of steatosis is an independent factor of fibrosis progression in untreated patients with chronic hepatitis C and paired liver biopsies. Gut 2003;52:288-92

9 Clouston AD, Jonsson JR, Purdie DM, et al. Steatosis and chronic hepatitis C analysis of fibrosis and stellate cell activation. J Hepatol 2001;34:314-20.

10 Westin J, Nordlinder $\mathrm{H}$, Lagging $M$, et al. Steatosis accelerates fibrosis development over time in hepatitis $C$ virus genotype 3 infected patients. $J$ Hepatol 2002;37:837-42.

11 Rubbia-Brandt L, Quadri R, Abid K, et al. Hepatocyte steatosis is a cytopathic effect of hepatitis $C$ virus genome 3. J Hepatol 2000;33:106-15.

12 Serfaty $L$, Andreani T, Giral $P$, et al. hepatitis $C$ virus induced hypobetalipoproteinemia: a possible mechanism for steatosis in chronic hepatitis C. J Hepatol 2001;34:428-34.

13 Perlemuter G, Sabile A, Letteron P, et al. Hepatitis $C$ virus core protein inhibits microsomal triglyceride transfer protein activity and very low density lipoprotein secretion: a model of viral-related steatosis. FASEB $J$ 2002; 16:185-94.

14 Caronia S, Taylor K, Pagliaro L, et al. Further evidence for an association between non-insulin-dependent diabetes mellitus and chronic hepatitis $\mathrm{C}$ virus infection. Hepatology 1999:30:1059-63.

15 Mason AL, Lau JYN, Hoang N, et al. Association of diabetes mellitus and chronic hepatitis C virus infection. Hepatology 1999;29:328-33.

16 Hadzyiannis S, Karamanos B. Diabetes mellitus and chronic hepatitis $C$ virus infection. Hepatology 1999;29:604-5.

17 Mehta SH, Brancati FL, Sulkowski MS, et al. Prevalence of type 2 diabetes mellitus among persons with hepatitis $C$ virus infection in the United States. Ann Intern Med 2000; 133:592-9.

18 Grimbert S, Valensi P, Levy-Marchal C, et al. High prevalence of diabetes mellitus in patients with chronic hepatitis $\mathrm{C}$ : A case-control study. Gastroenterol Clin Biol 1996;20:544-8.
19 Martin BC, Warram JH, Krolewski AS, et al. Role of glucose and insulin resistance in development of type 2 diabetes mellitus:results of a 25 -year follow-up study. Lancet 1992;340:925-9.

20 Petit JM, Bour JB, Galland-Jos C, et al. Risk factors for diabetes mellitus and early insulin resistance in chronic hepatitis C. J Hepatol 2001;35:279-83.

21 Hui JM, Sud A, Farrell GC, et al. Insulin resistance is associated with chronic hepatitis $C$ and virus infection fibrosis progression. Gastroenterology 2003; 125: 1695-704.

22 Shintani $\mathrm{Y}$, Fujie $\mathrm{H}$, Miyoshi $\mathrm{H}$, et al. Hepatitis $\mathrm{C}$ virus infection and diabetes: direct involvement of the virus in the development of insulin resistance. Gastroenterology 2004; 126:840-4.

23 Poupon RE, Schellenberg F, Nalpas B, et al. Assessment of the transferrin index in screening heavy drinkers from a general practice. Alcohol Clin Exp Res 1989; 13:549-53.

24 Matthews DR, Hosker JP, Rudenski AS, et al. Homeostasis model assessment: insulin resistance and beta-cell function from fasting plasma glucose and insulin concentration in man. Diabetologia 1985;28:412-29.

25 Emoto M, Nishizawa Y, Maekawa K, et al. Homeostasis model assessment as a clinical index of insulin resistance in type 2 diabetic patients treated with sulfonylureas. Diabetes Care 1999;22:818-22.

26 Bonora $E$, Targher $G$, Alberiche $M$, et al. Homeostasis model assessment closely mirrors the glucose clamp technique in the assessment of insulin sensitivity: studies in subjects with various degrees of glucose tolerance and insulin sensitivity. Diabetes Care 2000;23:57-63.

27 Merli M, Leonetti F, Riggio O, et al. Glucose intolerance and insulin resistance in cirrhosis are normalized after liver transplantation. Hepatology 1999;30:649-54

28 Bedossa P, Poynard T, The METAVIR Cooperative study group. An algorithm for the grading of activity in chronic hepatitis C. Hepatology 1996;24:289-93.

29 The French METAVIR Cooperative Study Group. Intraobserver and interobserver variations in liver biopsy interpretation in patients with chronic hepatitis C. Hepatology 1994;20:15-20.

30 Barry M, Sherlock S. Measurement of liver iron concentration in needlebiopsy specimens. Lancet 1971;1:100-3.

31 Petrides AS, Vogt C, Schulze-Berge D, et al. Pathogenesis of glucose intolerance and diabetes mellitus in cirrhosis. Hepatology 1994;19:616-27.

32 Neuschwander-Tetri BA, Caldwell SH. Nonalcoholic steatohepatitis: summary of an AASLD single topic conference. Hepatology 2003;37:1202-19.

33 An J, Muoio DM, Shiota M, et al. Hepatic expression of malonyl-CoA decarboxylase reverses muscle, liver and whole-animal insulin resistance. Nat Med 2004; 10:268-74.

34 Kahn BB, Flier JS. Obesity and insulin resistance. J Clin Invest 2000;4:473-81.

35 Petersen KF, Befroy D, Dufour S, et al. Mitochondrial dysfunction in the ederly: possible role in insulin resistance. Science 2003;300:1140-2.

36 Aytug S, Reich D, Sapiro LE, et al. Impaired IRS-1/PI3-Kinase signalling in patients with HCV: a mechanism for increased prevalence of type 2 diabetes. Hepatology 2003;38:1384-92.

37 Paradis V, Perlemuter G, Bonvoust $F$, et al. High glucose and hyperinsulinemia stimulate connective tissue growth factor expression: a potential mechanism involved in progression to fibrosis in nonalcoholic steatohepatitis. Hepatology 2001;34:738-44.

38 Fartoux L, Serfaty L, Lefevre G, et al. Steatosis, oxidative stress and fibrosis in chronic hepatitis C. Hepatology 2003;38:363A.

39 Day CP, James OF. Steatohepatitis: a tale of two"hits"? Gastroenterology $1998 ; 114: 842-5$

40 Lerat $H$, Honda $M$, Beard MR, et al. Steatosis and liver cancer in transgenic mice expressing the structural and non structural proteins of hepatitis $C$ virus. Gastroenterology 2002;122:352-65.

41 Letteron P, Fromenty B, Terris B, et al. Acute and chronic hepatic steatosis lead to in vivo lipid peroxidation in mice. J Hepatol 1996;24:200-8.

42 Okuda M, Li K, Beard MR, et al. Mitochondrial injury, oxidative stress, and antioxidant gene expression are induced by hepatitis $C$ virus core protein. Gastroenterology 2002;122:366-75

43 Ghany MG, Kleiner DE, Alter $\mathrm{H}$, et al. Progression of fibrosis in chronic hepatitis C. Gastroenterology 2003;124:97-104

44 Zarski JP, McHutchison J, Bronowicki JP, et al. Rate of natural disease progression in patients with chronic hepatitis C. J Hepatol 2003;38:307-14.

45 Lin HZ, Yang SQ, Chuckaree $C$, et al. Metformin reverses fatty liver disease in obese, leptin-deficient mice. Nat Med 2000;6:998-1003.

46 Neuschwander-Tetri BA, Brunt EM, Wehmeier KR, et al. Improved nonalcoholic steatohepatitis after 48 weeks of treatment with the PPAR- $\gamma$ ligand rosiglitazone. Hepatology 2003;38:1008-17. 